\title{
Modelagem Matemática nos anos iniciais da Educação Básica: uma discussão necessária
}

\begin{abstract}
Dionísio Burak
Márcio André Martins

\section{Resumo}

Este trabalho descreve aspectos favorecidos pela Modelagem Matemática enquanto Metodologia de Ensino, principalmente na Educação Básica, quando trabalhada na concepção de Educação Matemática que, por sua vez, envolve as Ciências Humanas. Busca, também, explicitar algumas das contribuições da Modelagem Matemática nos anos iniciais da Educação Básica. A fundamentação teórica assenta-se na Educação Matemática e no paradigma pós-moderno, a partir de alguns estudos realizados por pesquisadores da área, com vistas a uma prática educativa que envolva a Modelagem Matemática. Sugere algumas etapas para o encaminhamento de atividades com base em duas premissas norteadoras: a escolha do tema e a coleta dos dados, ambas caracterizadas pelo interesse do grupo ou grupos de estudantes. Discute a construção de Modelos no nível do Ensino Fundamental, apresenta um exemplo de problema e desenvolve a construção e discussão de um modelo matemático em sala de aula em duas situações, com os estudantes e com os professores.

Palavras-chave: Modelagem Matemática, Ensino e Aprendizagem, Anos Iniciais.

Abstract

Mathematical Modeling in the early years of Elementary school: a necessary discussion.

This paper describes aspects favored by Mathematical Modeling as a Teaching Methodology, particularly in Elementary school, in the conception of Mathematics Education which, in turn, involves the Humanities. Presents some of the contributions of Mathematical Modeling in the initial period of elementary school. The theoretical foundation is located in mathematics education and in the postmodern paradigm, from surveys conducted with a view to an educational practice involving the Mathematical Modeling. Suggests some steps for activities based on two fundamental principles: the theme choose and data collection, both characterized by an interest of the group or groups of students. Discusses the construction of models in the elementary school level and provides an example problem and develops the construction and discussion of a mathematical model in class in two situations: with students and with teachers.
\end{abstract}

Keywords: Mathematical Modelling, Teaching and Learning, Early Years. 


\section{Introdução}

No Brasil, a Modelagem Matemática começou a ser trabalhada na Universidade Estadual de Campinas - UNICAMP, na área de Biomatemática, por um grupo de professores coordenado pelo Prof. Dr. Rodney Carlos Bassanezi - do Instituto de Matemática, Estatística e Ciências da Computação - IMECC, ainda na década de 1980. No mesmo período, sob a mesma coordenação, também foi realizada uma experiência com a Modelagem em turmas regulares da UNICAMP. A primeira turma regular participante foi a de Engenharia de Alimentos, na disciplina de Cálculo Diferencial e Integral, que possuía conteúdo programático definido. Os resultados obtidos, segundo Bassanezi (2002), foram bastante satisfatórios e, animado com os primeiros resultados da experiência, o grupo ofereceu os primeiros cursos de especialização para professores em 1983, na Faculdade de Filosofia Ciências e Letras de Guarapuava - FAFIG, hoje Universidade Estadual do Centro-Oeste - UNICENTRO/PR.

Com o início do Programa de Mestrado em Ensino de Matemática pela UNESP - Campus de Rio Claro - SP, a Modelagem ${ }^{1}$ angariou outros adeptos, pois a grande meta para o ensino de Matemática sempre foi encontrar formas alternativas para uma aprendizagem mais próxima das situações vivenciadas pelo estudante do ensino de 1 으 e 2 o graus, níveis atualmente chamados de Ensino Fundamental e Médio. Esse entendimento, muitas vezes, foi e ainda é interpretado de maneira equivocada, pois, quando se diz partir de situações mais próximas do estudante significa dizer que é desejável partir das situações mais próximas do cotidiano do estudante e direcionar o ensino para as questões com as quais ele tenha maior familiaridade, sem que isso signifique, entretanto, nelas permanecer.

Os primeiros trabalhos enfocando a Modelagem como uma alternativa para o ensino de Matemática foram resultado de dissertações, provenientes delas ou, ainda, relacionados às experiências com os cursos para professores. A denominação alternativa para o ensino, empregada neste trabalho, significava, à época, a necessidade de se ter novas formas de ensinar Matemática e constituía-se pela necessidade de se oferecer uma nova opção para o ensino da Matemática.

Ao longo do tempo, a Modelagem vem sendo desenvolvida sob vários contornos em sala de aula e essas diferentes formas de concepção refletem as experiências vividas pelos seus seguidores. Assim sendo, a experiência e o nível de ensino em que o docente atua, seja no Ensino Superior ou na Educação Básica, oferecem características, percepções e encaminhamentos distintos ao trabalho com a Modelagem. É importante deixar claro que entendemos não haver uma concepção de Modelagem que seja mais verdadeira que outra, ou uma mais correta do que a

${ }^{1}$ Em alguns momentos deste trabalho, utilizaremos Modelagem para significar Modelagem Matemática.

R. B. E. C. T., vol 8, núm. 1, jan-abr.2015 ISSN - 1982-873X

DOI: Em andamento. 
outra, mas o que se coloca aqui é a necessidade de haver clareza quanto às concepções de "Homem", "Educação", "Ensino e Aprendizagem" e ao objeto de estudo, o que implica em questões epistemológicas que direcionam nossa prática educativa no âmbito dos distintos níveis e modalidades de ensino.

Neste trabalho, expressamos uma concepção sobre o trabalho com a Modelagem Matemática voltada, principalmente, à Educação Básica, na qual atuamos por muitos anos. Devemos, a bem da verdade, expressar que os fatores determinantes para a mudança na forma inicial de ver e conceber a Modelagem estão em conformidade com os princípios epistemológicos que norteiam a construção do conhecimento sob a perspectiva do paradigma pós-moderno e do pensamento complexo. Faz-se necessário também destacar que os objetos da Matemática e da Educação Matemática - cuja natureza envolve, além da Matemática, outras áreas que dão sustentação à educação - são distintos. Os objetos de estudo da Matemática, na perspectiva das Ciências Exatas e Naturais, visam à construção do conhecimento matemático diferentemente da Educação Matemática, que tem como meta o ensino e a aprendizagem de Matemática. Assim, torna-se necessário e conveniente que proclamemos nosso entendimento sobre a Modelagem Matemática na perspectiva da Educação Matemática, que é pautada pela visão das Ciências Humanas e Sociais. Esse entendimento torna-se imprescindível quando se trata da Educação Básica, cujo objetivo primeiro é a construção do conhecimento matemático pelos estudantes e não a preocupação com a aplicação desse conhecimento que, nesse nível de escolaridade, ainda está sendo construído. Nessa perspectiva, este artigo objetiva esclarecer, de forma satisfatória, alguns aspectos que consideramos fundamentais para a compreensão da Modelagem Matemática como uma Metodologia de Ensino de Matemática na perspectiva da Educação Matemática e voltada prioritariamente à Educação Básica.

Este artigo está estruturado de modo a contemplar, na introdução, um panorama geral da Modelagem Matemática na Educação Brasileira e, na sequência, fornecer subsídios sobre a Modelagem na perspectiva da Educação Matemática que, por sua vez, utiliza-se dos referenciais da Psicologia Cognitiva, do Pensamento Complexo de Morin (2006), da perspectiva dos trabalhos de Rius (1989a e 1989b), Kilpatrick (2006), Burak e Klüber $(2008,2010)$ e também do paradigma pós-moderno no entendimento de Santos (2006). Contempla, ainda, alguns esclarecimentos e exemplos em relação aos problemas e à construção de modelos a partir da concepção assumida.

\section{A Modelagem na perspectiva da Educação Matemática}

No propósito de facilitar o entendimento de Modelagem na Educação Matemática, trazemos elementos dos estudos de Rius (1989 a; 1989 b), Burak e Klüber (2008; 2010), Burak (2010) e Kilpatrick (2006), para subsidiarem tal empreendimento. Como se trata de um tema já divulgado em artigos, eventos, livros e periódicos, faremos uma breve retrospectiva para justificar 
nossa compreensão sobre a necessidade do ensino da Modelagem Matemática na Educação Matemática. Trataremos inicialmente sobre a natureza da Educação Matemática, cujas primeiras luzes foram trazidas por Higginson (1980), conforme Rius (1989a), com o seu "Modelo do Tetraedro", no qual as faces são constituídas pela Matemática e pelas áreas da Educação, dentre elas a Psicologia, a Sociologia e a Filosofia.

Dada a dinâmica da disciplina ${ }^{1}$ Educação Matemática, novas áreas do conhecimento foram a ela se incorporando, como a Antropologia, a Língua Materna, a História da Matemática, entre outras, e proporcionaram características e especificidades à Educação Matemática que, de forma natural, a afastaram-na do interior das Ciências Naturais, pois a natureza e o seu objeto de estudo são distintos do objeto da Matemática. Entretanto, muitos pesquisadores e autores consideram que o denominado Movimento Matemática Moderna, dos anos 70, é também um Movimento da Educação Matemática. Essa forma de considerar esses dois movimentos enseja o espaço para ressaltar, ainda que de forma abreviada, algumas considerações acerca das diferenças entre eles.

O Movimento Matemática Moderna, segundo Burak e Klüber (2009), atribuía uma importância fundamental à teoria dos conjuntos, à axiomatização, às estruturas algébricas e sua lógica apontava para uma visão mais voltada às estruturas matemáticas, denominada visão internalista. A grande mudança pretendida pelo $\mathrm{MMM}^{2}$ visava transferir as ideias gerais $\mathrm{e}$ unificadoras da matemática a níveis cada vez mais elementares. Essa visão de Matemática trouxe, e isso não se pode negar, contribuições positivas para o desenvolvimento de alguns campos da Matemática e para a solução de alguns problemas que há muito desafiavam os matemáticos. Uma prova disso é o fato de matemáticos do século passado estarem, ainda, ocupados com o que ficou conhecido como os sete problemas do Milênio que, segundo Delvin (2004), são o Monte Everest dos matemáticos.

A Educação Matemática, na forma assumida, mantém como preocupação primeira as questões voltadas para o ensino e para a aprendizagem da Matemática, todas de natureza complexa, pois deparamo-nos também com problemas, os mais diversos; não sabemos precisar quantos e nem quais deles devem ser catalogados como os mais importantes ou "difíceis" a serem colocados como desafio da Educação Matemática para o século XXI. Tais problemas permeiam os resultados emitidos pelos órgãos nacionais e internacionais que avaliam o desempenho em matemática dos nossos estudantes. Percebemos também que, muitas das vezes, órgãos oficiais apenas tangenciam os problemas com medidas paliativas, como por exemplo, favorecem o simples aumento da carga horária da disciplina nas escolas, mas deixam de lado

2 Nos trabalhos de Rius (1989a), alguns estudiosos denominavam a Educação Matemática como uma disciplina.

2 O Movimento Matemática Moderna também ficou conhecido como MMM ou três Ms.

R. B. E. C. T., vol 8, núm. 1, jan-abr.2015 ISSN - 1982-873X

DOI: Em andamento. 
aspectos importantes da formação inicial do professor na Licenciatura. Ressalte-se que, as muitas instituições de Ensino Superior que oferecem a Licenciatura em Matemática, na maioria das vezes, tratam-na como um Bacharelado, isto é, nelas, a Licenciatura é concebida como formadora de bacharéis que primam, tão somente, pela internalização de conteúdos matemáticos, desconsiderando completamente os objetos específicos de cada uma das modalidades. Ainda, com relação à formação de docentes que atuam nas séries iniciais (Licenciatura em Pedagogia), como pode ser constatado nas estruturas curriculares desses cursos, o ensino da Matemática não é entendido como um assunto que merece uma "atenção especial", ou seja, dada a problemática atual identificada no âmbito da Educação Matemática, as abordagens de ensino adotadas permanecem inalteradas com o passar dos anos. Isso caracteriza, de certo modo, a falta de diálogo e interação entre os educadores matemáticos - educadores e pesquisadores envolvidos essencialmente com questões inerentes ao ensino e à aprendizagem da Matemática - e os profissionais da educação que atuam, com prioridade, nas séries iniciais da Educação Básica.

Reafirmamos, por conviç̧ão epistemológica, que se uma transformação/revolução na educação acontecer será na sala de aula e não pela sua negação. Podemos, então, admitir que o nosso repto tenha consequências também significativas na comunidade e na sociedade, além de concordarmos com Freire (1987), quando expressa que se a escola sozinha não muda a sociedade, tampouco esta mudará sem a escola. No entanto, sob o ponto de vista de Ramos (1994), a escola está pronta para mudar, em conformidade com a sociedade, pois atende às três condições entendidas como necessárias à mudança: 1) a escola, enquanto instituição vem sofrendo enormes pressões externas; 2 ) os membros que compõem a escola demonstram-se insatisfeitos, de modo geral; 3) existem alternativas sendo propostas por educadores-pesquisadores, com relação ao ensino e a aprendizagem no domínio escolar.

Os problemas que envolvem o ensino e a aprendizagem da Matemática, não importando o nível de escolaridade, conduzem a uma preocupação com o ser humano que entendemos ser, em acordo com Morin (2006), ao mesmo instante, de natureza física, biológica, psíquica, cultural, social e histórica, o que acrescenta maior complexidade à questão. Essas características, ao serem consideradas em uma prática educativa, podem exigir tanto esforços quanto qualificação, uma vez que, além de tratarem do conteúdo, devem contemplar aspectos dos sujeitos individual e coletivo, presentes no contexto escolar. Para Edgar Morin (2006), "esta unidade complexa da natureza humana" tem sido totalmente desintegrada na educação por meio das disciplinas que não dialogam entre si e acabam mutilando a visão do todo.

É nessa perspectiva que vemos a Educação Matemática ainda padecendo dos mesmos problemas e preocupações que inspiraram a criação do Movimento Educação Matemática; dentre eles, figuram suas maiores preocupações: o ensino e a aprendizagem da Matemática. Essas preocupações são plenamente justificáveis, pois seu ensino ainda se encontra numa perspectiva disciplinar; sendo tratado como problema quase que exclusivamente de técnica. $O$ ensino a que 
nos referimos não é o ensinar por ensinar, mas um ensino que conduza a uma formação crítica, que conduza a uma libertação, que conduza ao confronto necessário a favor de uma humanização daqueles que frequentam a escola e são membros constituintes da sociedade (FREIRE, 1983).

Para nós, educadores matemáticos, grandes desafios são apresentados: Urge identificarmos, discutirmos e realizarmos estudos nos/dos problemas detectados no ensino, com vistas à aprendizagem de uma Matemática que solicite dos estudantes a construção e o desenvolvimento de suas capacidades. Para tanto, é necessário que haja a prática de um pensar que contemple, além do matemático, uma visão transdisciplinar e promova "o conhecimento capaz de apreender os problemas globais e fundamentais para neles inserir os conhecimentos parciais e locais" (MORIN, 2006, p.14). Essa prática só ocorrerá com a criação de situações que estimulem o desenvolvimento da autonomia do estudante, com estratégias próprias que levemno a buscar a solução para uma dada situação-problema, que favoreçam conjecturas e a atribuição de significado ao conteúdo aprendido, além da apropriação gradativa de um conhecimento não mais fragmentado, mas interdisciplinar e holístico, capaz de operar vínculos entre as partes e a totalidade. Nessa mesma perspectiva, é preciso incentivá-lo a articular os vários significados de um mesmo conceito às diferentes representações matemáticas, envolvendo língua materna, linguagem simbólica, desenhos, gráficos e tabelas.

É com essa visão que se pretende conduzir o estudante à construção de algumas competências complexas importantes para o momento do mundo atual, tais como: saber observar, explorar e investigar; estabelecer relações, classificar e generalizar e, ainda, favorecer situações que permitam desenvolver capacidades de argumentar, tomar decisões e criticar, ou seja, conforme Morin (2006), que habilitem o estudante a enfrentar situações novas, inusitadas e as incertezas, os imprevistos e o inesperado, a partir de informações construídas ao longo do tempo. Para o referido autor, é importante que todos os que se ocupam da educação constituam a vanguarda ante a incerteza de nossos tempos. É, também, uma necessidade de nossos tempos induzir os estudantes a situações desafiadoras, que reclamem o uso da imaginação e da criatividade e desenvolvam suas capacidades de expressão, reflexão e crítica.

Percebe-se, nesse discurso, uma tendência centrada na atribuição de "sentido" às ações desenvolvidas que, como bem pontua Panizza (2006), é frequente nas indagações e problemáticas vivenciadas pelos educadores matemáticos, como exemplos: Os alunos não veem sentido na atividade matemática vista em sala de aula; $A$ repetição simples e mecânica de um algoritmo não faz sentido ao ensino da Matemática contemporânea. Nesse contexto, a palavra 'sentido' busca explicitar finalidades, conquistas e insatisfações, porém, o seu real significado não é de domínio exclusivo do docente ou do aluno, mas de ambos em uma postura autocrítica e colaborativa.

Outros pontos podem ser acrescidos ou contemplados no objeto da Educação Matemática, os quais se constituem, segundo nosso entendimento, em práticas desejáveis do 
professor no processo de ensino com vistas a uma aprendizagem significativa. Assim, espera-se que esse profissional seja:

1) Organizador, quando, para encaminhar as atividades transforma-se em um pesquisador da "realidade" do estudante, o que implica em conhecer aspectos relativos às condições socioculturais dos estudantes sob a sua responsabilidade, as suas expectativas, o desenvolvimento cognitivo destes, bem como seus interesses e, com base nesse conhecimento, escolher e selecionar situações e ações adequadas que possibilitem a formação de conceitos que, em crianças pequenas, segundo a teoria Ausubeliana, é o principal processo de aquisição de conceitos, conforme Novak (1981), enquanto nas crianças com idades mais avançadas a maioria dos novos conceitos é adquirida através da assimilação, diferenciação progressiva e reconciliação integrativa;

2) Mediador, aquele a quem cabe estabelecer a ponte entre o conhecimento construído historicamente e o conhecimento do educando. Para isso, espera-se que o profissional torne-se promotor de discussões e debates sobre resultados, estratégias e métodos utilizados pelos educandos, oriente as reformulações, valorize e discuta as soluções encontradas, oferecendo ao estudante a oportunidade de rever os procedimentos adotados e reconhecer uma solução mais adequada;

3) Incentivador, qualidade que requer o estímulo e a orientação à prática cooperativa entre os estudantes, no incentivo às trocas e ao confronto de ideias, bem como às argumentações, oferecendo e indicando textos, materiais e informações para fundamentá-las;

4) Problematizador, que busca e cria novas hipóteses sobre as situações discutidas, desafiando e instando os estudantes à investigação sobre os conteúdos estudados com perspectivas de aprofundamento e conhecimento;

5) Avaliador, quando, no sentido de identificar e conferir significados às manifestações dos estudantes, por meio de instrumentos distintos e adequados e ainda de observações, promove checagem de conteúdos em situações contextualizadas, relativas ao seu progresso em Matemática, dedicando-se, portanto, a conhecer o sujeito que aprende. Tal prática figura como uma oportunidade de o professor avaliar o processo de ensino, reorientar métodos, técnicas e materiais, sempre que forem constatadas diferenças entre o que se espera e o que o estudante apresenta como aprendizagem.

Para que essas capacidades se façam presentes no ensino e aprendizagem da Matemática, nos diversos níveis e modalidades de ensino, alguns desafios nos são impostos: 1 ) Conhecer para poder discernir o objeto de estudo da Educação Matemática na perspectiva da visão internalista que promove a relação das ciências naturais com o objeto de estudo da Educação Matemática na perspectiva de um ensino/aprendizagem que pressuponha um diálogo mais efetivo com as ciências humanas e sociais; 2) Distinguir e promover estudos de bases 
epistemológicas, sociológicas, psicológicas, filosóficas, educacionais e até mesmo ambientais, que possam fundamentar uma prática pedagógica que favoreça a construção de capacidades desejáveis para um cidadão do século XXI; 3) Conhecer as proposições de transformação da Educação, particularmente as pertinentes ao campo da Pesquisa em Educação Matemática; e 4) Reorientar a formação de profissionais de modo a fazer frente às necessidades atuais da sociedade, implicando em construir um novo perfil do professor e da escola.

Desse modo, um olhar mais atento permite notar que as proposições expõem uma preocupação permanente com a busca por uma Educação Matemática com qualidade, capaz de considerar os problemas fundamentais da educação e de ter clareza na forma de articular e organizar o conhecimento, pois, para reconhecer e conhecer os problemas do mundo, é necessário que haja uma reforma do pensamento. Entretanto, essa reforma é paradigmática e não programática: “é a questão fundamental da educação, já que se refere a nossa aptidão de organizar o conhecimento" (MORIN, 2006, p.35).

Além disso, a esse problema universal, sobre o conhecimento que diz respeito a todo cidadão do novo milênio, como ter acesso às informações sobre o mundo e como ter a possibilidade de articulá-las e organizá-las, perceber o contexto, o global e o complexo, acrescenta-se a necessidade de uma educação do futuro, pois, para Morin (2006, p. 36),

"existe inadequação cada vez mais ampla, profunda e grave entre, de um lado, os saberes desunidos, divididos, compartimentados e, de outro, as realidades ou problemas cada vez mais multidisciplinares, transversais, multidisciplinares, transnacionais, globais e planetários e nessa inadequação tornam-se invisiveis: o contexto; o global; o multidimensional e o complexo".

Muito embora já se anuncie desde o final do século passado, somente agora observamos a emergência tímida, mas gradual, de um paradigma que confere uma nova visão e atribui às Ciências Sociais uma nova centralidade na busca de um novo senso comum (SANTOS, 2006). É na perspectiva da visão de um novo campo de estudos que incluímos a Educação Matemática e suas implicações à Modelagem Matemática, concebida com vistas ao ensino e a aprendizagem de Matemática.

Ao educador matemático se impõe uma tarefa: conhecer as bases que sustentam uma prática capaz de possibilitar o desenvolvimento de capacidades no sujeito e que o preparem para a transformação tão esperada no âmbito da Educação, com a ressalva de que isso não será conseguido sem a contribuição de outras áreas do conhecimento. Na qualidade de Educadores Matemáticos, não desejamos nem admitimos uma Educação Matemática sem a Matemática; no entanto, não podemos também concebê-la sem a presença de outras áreas que a fundamentam, justamente por estarmos substantivados pela Educação. 
A este propósito, uma frase de Higginson, em Rius (1989a), que a cada dia mais nos convence pela verdade que encerra: não haverá avanços significativos em Educação Matemática, nas questões do ensino e da aprendizagem, até que se compreendam os fundamentos das áreas que a constituem. Esta questão, juntamente com outras já mencionadas, explícita ou implicitamente, solicita de todos nós estudos, discussões e reflexões conjugados com respectivas ações propositivas em sala de aula.

É justamente nessa perspectiva de um ensino e aprendizagem que vamos tratar da Modelagem Matemática, no âmbito da Educação Básica, numa concepção de Educação Matemática, cuja natureza e método sejam fundamentos para a efetivação de uma prática educativa coerente e consistente.

\section{A Modelagem Matemática e a sala de aula}

A partir da concepção de Modelagem enquanto Metodologia de Ensino, proposta por Burak (1992, 2012) e Burak e Kluber (2008), que tem como balizadora a perspectiva de Educação Matemática que se orienta pelas Ciências Humanas e Sociais, o presente trabalho parte dos seguintes princípios: 1) O interesse do grupo ou dos grupos; e 2) Os dados são coletados onde se dá o interesse do grupo ou dos grupos. O "interesse", entendido como ponto de partida para o desenvolvimento de qualquer atividade humana, neste caso, particularmente, permitiu que a Modelagem Matemática encontrasse na Psicologia argumentos que o consolidam como princípio sustentador dos procedimentos metodológicos adotados.

$\mathrm{Na}$ forma usual, o processo de ensino é deflagrado pelo professor; na Modelagem Matemática, na perspectiva assumida, o processo é compartilhado com o grupo de estudantes, pois sua motivação advém do interesse pelo assunto. Daí, decorrem aspectos importantes a serem destacados:

- Maior interesse do(s) grupo(s). O fato de o grupo compartilhar o processo de ensino, isto é, escolher aquilo que gostaria de estudar, ter a oportunidade de se manifestar, de discutir e propor ideias desenvolve o interesse de cada grupo e dos grupos;

- Interação maior no processo de ensino e de aprendizagem. Para a aprendizagem, o procedimento gerado a partir do interesse do grupo ou dos grupos parece resultar em ganho, pois o grupo ou os grupos de alunos trabalham com aquilo que gostam e que para eles apresenta significado, por isso, tornam-se corresponsáveis pela aprendizagem;

- Dá-se também a manifestação de uma forma distinta de conceber a educação e, em consequência, a adoção de uma nova postura do professor.

Diferentemente do ensino usual, na Modelagem Matemática o fato de haver a possibilidade de compartilhar o processo de ensino com o grupo ou grupos é essencial, pois 
favorece o estabelecimento de relações afetivas mais fortes entre os estudantes e, destes, com o professor.

\section{Desenvolvimento do trabalho com a Modelagem em aula}

Para fins de encaminhamento do trabalho ou das atividades em aula, sugere-se que a Modelagem Matemática contemple cinco etapas:

- escolha do tema;

- pesquisa exploratória;

- levantamento dos problemas;

- resolução do(s) problema(s) e o desenvolvimento da matemática relacionada ao tema;

- análise crítica da(s) solução(es).

O trabalho com a Modelagem Matemática parte de temas propostos pelo grupo, ou pelos grupos constituídos por 3 a 4 participantes. Nessa perspectiva, o ensino de Matemática torna-se dinâmico, mais vivo e, em consequência, mais significativo para o estudante e para o grupo, pois contribui para tornar mais intensa, mais eficiente e mais eficaz a construção do conhecimento por parte de cada participante do grupo, do próprio grupo ou dos grupos, sobre determinado conteúdo, a partir do conhecimento que cada aluno ou o grupo já possui sobre o assunto. Sob essa ótica, de considerar a individualidade e/ou a diversidade dos alunos, há que se ressaltar a importância do fator motivacional, primeiramente, por parte do professor, que deve adotar um tratamento individualizado de encaminhamentos e objetivos. Isso confere maior significado ao contexto, permitindo e favorecendo o estabelecimento de relações matemáticas, bem como a compreensão dessas relações.

Há, ainda, a possibilidade de uma dinâmica maior no ensino, pela ação e pelo envolvimento do próprio grupo na perspectiva da busca da construção do conhecimento e por meio da socialização desse conhecimento no âmbito do próprio grupo e, posteriormente, aos demais grupos.

Nessa configuração de encaminhamento concebido pela Modelagem Matemática, enquanto metodologia para o ensino de Matemática na Educação Básica, a ação do professor fica redefinida, pois este passa a se constituir como mediador entre o conhecimento matemático elaborado e o conhecimento do aluno ou do grupo. Isso se diferencia do ensino usual ou de algumas outras formas de conceber a Modelagem nas quais, na maioria das ações, o professor ainda é o centro do processo.

Na Modelagem, o conteúdo matemático a ser trabalhado é determinado pelos problemas levantados em decorrência da pesquisa de campo, in loco, que pode ser complementada por diversas mídias: entrevistas, pesquisas em textos impressos, em sites, em vídeos, entre outros, que se constituem na $2^{\text {a }}$ etapa, denominada pesquisa exploratória. 
Dessa forma, no levantamento do(s) problema(s) da 3a etapa, se a questão, por exemplo, é a comparação de preços entre vários produtos, os conteúdos trabalhados e necessários para realizar essa comparação ganham importância e significado para o estudante. Essa forma de encaminhar as atividades na Modelagem apresenta caminhos e encaminhamentos distintos do verificado usualmente, isto é, na forma concebida de Modelagem são os problemas ou as situações-problema que determinam os conteúdos a serem estudados e isso difere dos encaminhamentos habituais no ensino usual, no qual o conteúdo estabelecido no programa é que determina o tipo de problema a ser a abordado.

No enfoque adotado, a Modelagem Matemática rompe com a forma usual de se conduzir o ensino de Matemática. Entretanto, essa forma diferenciada pode também se constituir em motivo de apreensão entre os professores, já que os conteúdos programáticos de determinada série poderão nem sempre ser os mesmos levantados pelo(s) grupo(s). Com os procedimentos da Modelagem Matemática, muitas vezes, é necessário compatibilizar o conteúdo estabelecido para determinada série, que se apresenta logicamente ordenado e determinado, com a proposta de preconizar o problema como determinante do conteúdo.

Isso, sem dúvida, apresenta-se como um grande desafio a ser enfrentado e superado pelos professores e pela escola, uma vez que as próprias Diretrizes Curriculares Nacionais, em conformidade com a forma de conceber a Modelagem ao tratar do ensino dessa disciplina na Educação Básica, apontam caminhos que desafiam e rompem com a forma usual de se conceber o estudo de Matemática. Também é verdade que essa ruptura perpassa pela mudança na concepção de educação, de ensino e de aprendizagem, do professor.

"[...] o ensino de Matemática prestará sua contribuição, à medida que forem exploradas metodologias que priorizem a criação de estratégias, a comprovação, a justificativa, a argumentação, o espírito crítico, e favoreçam a criatividade, o trabalho coletivo, a iniciativa pessoal e a autonomia advinda do desenvolvimento da confiança na própria capacidade de conhecer e enfrentar desafios" (BRASIL, 2000, p. 31).

Dessa forma, a adoção da Modelagem Matemática como uma metodologia para o ensino de Matemática almeja contribuir para que, de forma gradativa, seja superado o tratamento estanque e compartimentalizado, pois, na adoção dessa metodologia, um conteúdo matemático pode se repetir várias vezes no transcorrer das várias atividades em momentos e situações distintas, além de não seguir uma sequência linear, o que favorece a compreensão das ideias fundamentais e contribui de forma significativa para a percepção da importância da Matemática no cotidiano da vida de cada cidadão, seja ele ou não um matemático.

A Modelagem enseja, ainda de forma natural e indissociável, o ensino e a pesquisa. Ao favorecer o trabalho com temas diversos, de livre escolha do grupo ou dos grupos, ela favorece a ação investigativa como possibilidade de conhecer, compreender e atuar naquela realidade. 
Entendemos que não se pode intervir de maneira adequada numa realidade que não se conhece. Assim, a abordagem de um tema exige o conhecimento das várias dimensões ou aspectos que compõem a realidade tratada. Por exemplo, ao trabalhar com o tema a "indústria cerâmica", procura-se conhecer as várias dimensões que constituem essa realidade, sejam elas políticas, sociais, econômicas e estruturais, ambientais, entre outras.

Essas dimensões são levantadas na pesquisa de campo, na etapa que denominamos pesquisa exploratória. A coleta dos dados e informações proporcionam elementos à análise predominantemente qualitativa e favorece as constatações que, por sua vez, geram necessidade de outras comprovações.

Esta etapa da Modelagem se configura como de suma importância para o desenvolvimento, no grupo ou nos grupos, da experiência de campo, ajudando a formar nos estudantes um comportamento mais atento, mais sensível e mais crítico, tornando-os capazes de realizar uma leitura mais apurada da realidade, atributos importantes na formação de um pesquisador. A ação investigativa, ao traduzir em dados quantitativos, algumas observações, pois grande parte da natureza dos dados é descritiva, confere nova conotação aos dados numéricos obtidos e possibilita a discussão e o estabelecimento de relações e padrões, que contribuem para o desenvolvimento de um pensar lógico e coerente.

\section{Sobre os Problemas na Modelagem Matemática}

$\mathrm{Na}$ Modelagem Matemática, os problemas apresentam características distintas dos problemas apresentados na maioria dos livros-texto, pois são consequência da coleta dos dados, de natureza qualitativa ou quantitativa, provenientes da pesquisa exploratória:

- são elaborados a partir dos dados coletados na pesquisa de campo;

- possuem, geralmente, caráter genérico;

- estimulam a busca e a organização dos dados;

- favorecem uma compreensão mais ampla de determinada situação.

Um exemplo de problema levantado por um determinado grupo de estudantes consistia em calcular o custo de transporte do barro até o local onde se fabricavam telhas e tijolos. Esse problema ensejou a discussão e o levantamento de, pelo menos, dois aspectos iniciais à questão:

- qual distância entre o local onde se encontra o barro até onde são fabricadas as telhas e tijolos?

- qual(is) o(s) meio(s) de transporte possíveis de serem usados?

A partir daí, surgiram outros aspectos relativos à questão, inclusive o levantamento de hipóteses, tais como: o transporte pode ser realizado por caminhão, carroça, vagonete, algum 
sistema mecânico, entre outros. A análise de cada uma das hipóteses levantadas pode ocasionar, ainda outras. Tomemos, a título de exemplo, a hipótese de que o transporte seja feito por caminhão. De forma natural, entre os participantes, surgiram questões, tais como: a) Qual a capacidade do caminhão? b) Qual tipo de combustível é utilizado? c) Qual a necessidade de consumo da indústria? d) Qual o consumo de combustível do caminhão nas seguintes hipóteses: $d_{1}$ ) Quando está carregado? $d_{2}$ ) Quando está vazio? e) Qual o tempo gasto na locomoção e no carregamento do material? Percebe-se que a cada hipótese colocada, novas questões e oportunidades de discussões surgem em relação à situação colocada. E, essa ramificação de questões e hipóteses caracteriza um cenário riquíssimo de aprendizado em que a pesquisa, propriamente dita, é vivenciada pelos envolvidos - professor e estudantes.

$\mathrm{Na}$ Modelagem Matemática, a resolução de problemas e o desenvolvimento da Matemática relacionada ao tema constituem-se em uma das etapas do processo sugerido para o encaminhamento do trabalho. Esta se constitui na 4a etapa do processo, sendo que os problemas elaborados com base nos dados coletados determinarão os conteúdos a serem trabalhados para as suas soluções.

Dessa forma, ganha sentido e significado cada conteúdo matemático utilizado na busca da solução do problema ou dos problemas. Ainda, no contexto do tema escolhido, podem ser desenvolvidos vários conteúdos matemáticos, ou não, provenientes dos dados coletados e a partir das hipóteses levantadas pelo professor e/ou pelo(s) grupo(s).

Na Modelagem Matemática, esse momento é fundamentalmente rico, pois favorece o trabalho com os conteúdos matemáticos que assim ganham significado. Muitas vezes, um conteúdo matemático não faz parte do ano/série em estudo. Nesse caso, o professor deve trabalhar o conceito, descobrir/investigar o que os estudantes conhecem a respeito do assunto e, por meio de atividades, proporcionar-lhes os conhecimentos prévios, de modo a possibilitar uma compreensão adequada para a solução da questão em pauta.

\section{Sobre a construção dos Modelos Matemáticos}

Consideramos que, no Ensino Fundamental, tanto nas séries iniciais como nas finais, a prioridade deve ser a construção do conhecimento matemático, que inclui a formação de conceitos, a ideia de número, a construção das propriedades dos números e das figuras, a construção dos pensamentos geométrico e algébrico, dentre outros. Desse modo, o trabalho com modelos dependerá do nível de ensino trabalhado e, ainda, de outras circunstâncias, pois no nível de ensino considerado - anos iniciais e finais da Educação Básica, utilizamos, na maioria das vezes, os modelos prontos, como exemplo: as expressões matemáticas para o cálculo de área de uma superfície e de equações lineares e quadráticas, dentre outras. 
Entretanto, esta etapa deve considerar o desenvolvimento e o ajuste de expressões e/ou operações matemáticas para se examinar melhor e mais adequadamente um caso em estudo. Essa oportunidade de construção constitui-se num momento privilegiado e rico para a formação do pensar matemático. Sobre isso, um aspecto que merece destaque diz respeito ao incentivo e ao desenvolvimento da capacidade de generalização, ou seja, de 'tornar geral' a utilização de um modelo utilizado para um caso específico, considerando outros casos que podem ser gerados, apenas, pela mudança de parâmetros (peso, altura, e medidas de modo geral). Como exemplo, a mudança de preço de um material empregado no revestimento de determinada superfície, cujo modelo envolve o cálculo da área bem como o custo associado.

Nessa forma de conceber a Modelagem, a ideia de modelo fica ampliada, constituindo-se como uma representação. Assim, tanto uma tabela de supermercado como a planta baixa de uma casa podem representar um modelo, embora, não se possam construir modelos preditivos, aqueles permitem tomadas de decisão, pois contemplam aspectos inerentes à analise descritiva de dados, ou seja, que preocupa-se com a compreensão de todos os aspectos envolvidos, desde a identificação de padrões de regularidade, aleatoriedade, até as consequências decorrentes apenas da variação de determinada medida de interesse. Além disso, nesse nível de ensino, em muitas situações, a linguagem habitual num primeiro momento pode substituir a linguagem simbólica e expressar a ideia de modelo, por exemplo, o preço a pagar por certa quantidade de combustível é igual ao preço unitário do litro desse combustível, pelo número de litros do combustível. Preço a pagar é igual ao valor de um litro, que multiplica o número de litros desse combustível. Assim, a linguagem é importante para a construção de expressões matemáticas e, em muitos casos, representa um modelo.

\section{Exemplos de construção de modelos matemáticos}

O exemplo de construção de modelo que será apresentado a seguir deu-se de duas formas: Inicialmente, a situação em estudo foi vista empiricamente com os professores e educandos, pois se tratava de um trabalho de 4a série, atualmente 5o ano, em que pretendiam cercar um campo de futebol. Sobre os encaminhamentos dados à situação:

- foi feito o desenho de parte do comprimento da cerca, mais precisamente $1 \mathrm{~m}$ (um metro), em cartolina;

- nesse $1 \mathrm{~m}$, foram colocadas (representadas) "as ripas" - retângulos de cartolina de $1,20 \mathrm{~m}$ de altura por $10 \mathrm{~cm}$ de largura;

- a largura do intervalo - distância entre duas ripas - foi neste caso, igual à largura da ripa, ou seja, $10 \mathrm{~cm}$;

- foi contado o número de ripas necessárias para cobrir $1 \mathrm{~m}$ do perímetro do campo.

R. B. E. C. T., vol 8, núm. 1, jan-abr.2015 ISSN - 1982-873X

DOI: Em andamento. 
- foi estabelecida uma regra de três (relação linear) para determinar o número de ripas necessárias para cercar o campo.

Essa ação, envolvendo os estudantes, foi significativa para a compreensão da situação investigada, especialmente para a compreensão da ideia matemática subjacente. No modelo ${ }^{1}$ de papelão (cartolina), foram necessárias 5 ripas para cobrir $1 \mathrm{~m}$ de comprimento da cerca. A ideia matemática de proporcionalidade presente nas discussões se fez clara - se em um metro foram necessárias 5 ripas, para $2 \mathrm{~m}$ seriam 10, para $3 \mathrm{~m}$ seriam 15 ripas, e assim por diante. Para um perímetro de 128 metros, portanto, seriam necessárias 640 ripas (128 55 ripas). Com os alunos, foi estabelecida uma regra de três simples, a partir da ideia de proporção para o cálculo do número de ripas. Outras hipóteses poderiam ser colocadas e discutidas com os estudantes, como a extensão/generalização dessa ideia para o cerco de um outro perímetro qualquer e, talvez, a identificação/percepção da necessidade de uma linguagem simbólica com o intuito de possibilitar uma representação geral. A aula oportunizou um momento profícuo de discussões e troca de ideias.

Num segundo momento, foi construído, com os professores, um modelo genérico, isto é, uma expressão matemática que buscasse representar a situação em estudo:

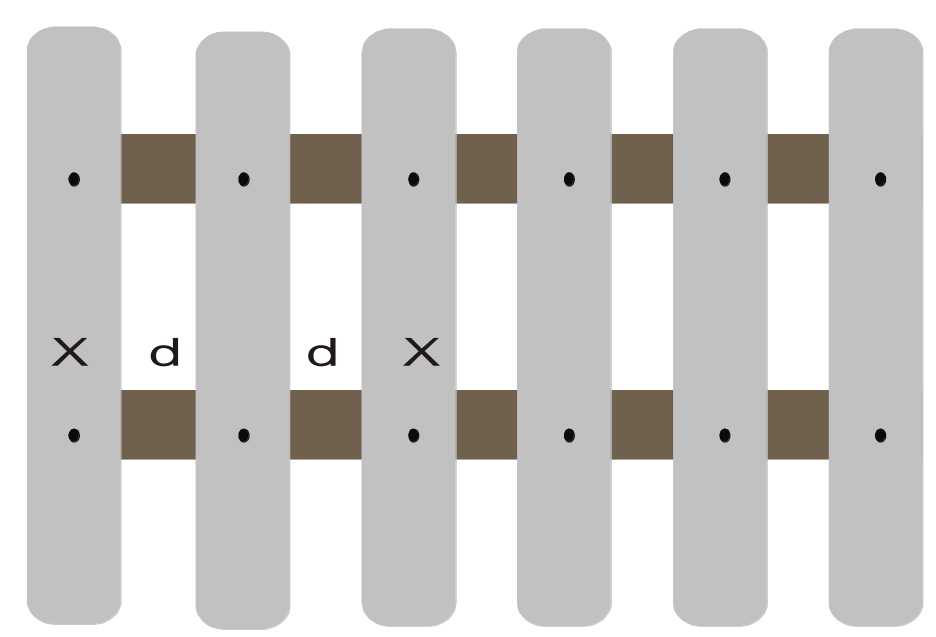

Figura 1 - Modelo genérico da cerca.

- Denominamos que $x$ seria a largura de cada ripa, isto é, uma largura qualquer;

\footnotetext{
${ }^{1}$ Tal modelo pode ser denominado icônico ou reduzido. Representa, no caso, a cerca em dimensões menores, mas é capaz de fornecer detalhes e explicação sobre a sua construção.
} 
- Denominamos $d$ a distância entre duas ripas consecutivas, ou seja, a distância do intervalo.

Passamos, então, ao processo de construção do modelo usando a abordagem empregada com os estudantes como ponto de partida.

Tabela 1 - Construção do modelo.

\begin{tabular}{cc} 
Número de ripas & Número de intervalos \\
\hline 1 & 0 \\
2 & 1 \\
3 & 2 \\
$\cdots$ & $\cdots$ \\
$n-1$ & $n$ \\
$n$ & $n-1$ \\
\hline
\end{tabular}

É imprescindível observar que o processo de construção deve ser compreendido pelos participantes. A Figura 1 serviu de base para a construção da Tabela 1, feita pelos professores.

Para estabelecer um comprimento $C$ qualquer da cerca, precisamos compreender alguns aspectos, que podemos chamar de variáveis e envolvem a largura da ripa e a largura do intervalo. Com essa perspectiva, foi escrito: comprimento qualquer é igual ao número ripas vezes a largura de cada ripa mais o número de intervalos vezes a distância de cada intervalo. Em uma ação de tradução da linguagem habitual para a representação simbólica tem-se: comprimento qualquer = número de ripas • a largura de cada ripa; + o número de intervalos • a distância de cada intervalo que, conforme a Tabela 1, é sempre igual ao número de ripas menos 1 (o símbolo • representa a expressão de multiplicação para não confundir com $o x$ da largura). Então, em um processo compreensivo,

$$
C=n \cdot x+(n-1) \cdot d, \text { ou } C=n x+d(n-1)
$$

Assim, para o cálculo de um comprimento $C$ qualquer, $1 m, 2 m, 3 m, \ldots, n m$, levando em consideração o visto anteriormente e traduzindo a linguagem corrente em expressão matemática, temos: $C$ é o comprimento qualquer, finito; $n$ é o número de ripas; $x$ é a largura da ripa; e $d$ é a distância entre duas ripas consecutivas. Então, em linguagem matemática temos: $C=$ comprimento; $n x$ representa número de ripas vezes (multiplicado pela) a largura da ripa; $d(n-1)$

DOI: Em andamento. 
(corresponde a) distância dos intervalos multiplicada pelo número de intervalos que é sempre ( $n$ $1)$.

Passando para uma linguagem algébrica:

$$
\begin{gathered}
C=n x+d(n-1), \text { eliminando o parêntese, } \\
C=n x+d n-d, \text { fatorando a expressão, } \\
C=n(x+d)-d .
\end{gathered}
$$

Esta expressão matemática denomina-se modelo matemático, onde $n \in N, n \geq 1, x, d$ e $C$ representam as variáveis de interesse. Porém, novas hipóteses com relação à situação em estudo implicam na elaboração/construção de novos modelos. Um exemplo, como fica o modelo quando a largura da ripa for igual à largura do intervalo? Na Equação (2), conforme a hipótese lançada,

$$
x=d: C=n(x+x)-x
$$

Simplificando e fatorando, temos

$$
C=(2 n-1) x,
$$

que representa o modelo matemático associado à última situação em estudo.

A validação do modelo é importante e permite o seu uso para outras situações análogas. O processo de "validação", aqui, é entendido como a comparação entre a solução matemática resultante e o problema real, ou seja, em testar a efetividade do modelo. Para validar um modelo, normalmente, utilizamos duas ou três situações. Neste caso, com uma ripa, $n=1$, duas ripas $n=2$ e, cinco ripas, $n=5$, por exemplo. Então, substituindo $n$ por 1, 2 e 5 na Equação (3) temos, respectivamente: $C=x$, isto é, o comprimento se resume à largura da ripa; $C=3 x$, o comprimento é igual a 3 vezes a largura da ripa; e $C=9 x$, ou seja, o comprimento será 9 vezes a largura da ripa. Isso pode ser comprovado empiricamente com base na Figura 1, para $x=d$. Passando para uma situação real, em que a ripa tem largura de $8 \mathrm{~cm}$, a largura de cada intervalo sendo também $8 \mathrm{~cm}$, as medidas dos comprimentos serão respectivamente: $8 \mathrm{~cm}, 24 \mathrm{~cm}$ e $72 \mathrm{~cm}$, ou traduzindo em metros $0,08 m, 0,24 \mathrm{~m}$ e $0,72 \mathrm{~m}$. 
No caso em estudo, para $1 \mathrm{~m}$ de comprimento de cerca quantas ripas seriam necessárias, considerando-se ripas de $8 \mathrm{~cm}$ de largura e a mesma medida aplicada no espaçamento, ou seja, $8 \mathrm{~cm}$ de distância entre duas ripas? Assim, $C=1 \mathrm{~m}=100 \mathrm{~cm}, x=8 \mathrm{~cm}, d=8 \mathrm{~cm}$. Então, utilizando a Equação (3), temos: $100=8(2 n-1)$ ou $100=16 n-8$, o que acarreta em $16 n=92$ ou $n=5,75$.

Como $n$ é o número de ripas, a situação envolveu a discussão sobre grandezas contínuas e discretas. Como fica a situação com 5 ou 6 ripas, pois o número de ripas somente pode ser 1, 2, 3 ,..., $n$, com $n \in N *$ (Naturais não nulos). A etapa denominada Análise crítica da(s) solução(ões), enseja a excelente oportunidade para discussão da situação: seriam então, 5 ou 6 ripas? Essas e outras discussões são oportunas nessa etapa da Modelagem Matemática e correspondem à possibilidade de se discutir a solução do problema, trazer às discussões conceitos sobre grandezas contínuas e discretas e questões entre outras: como fica a solução de uma questão que envolve essas grandezas? Qual a relação dessas com o estudo dos conjuntos numéricos? É também a oportunidade de se levar à discussão outros aspectos que não se relacionam somente com os matemáticos, por exemplo, a forma de utilização do local, a responsabilidade e a conservação do espaço conquistado, sobre o meio ambiente e a utilização das reservas de madeiras, reflorestamento, entre outros pontos.

Retornando à questão inicial, como o perímetro do espaço destinado à quadra era $128 \mathrm{~m}$, então surgiram várias possibilidades de se chegar ao cálculo da quantidade de ripas. As ideias matemáticas necessárias à resolução do problema dão também sentido e significado ao conteúdo matemático utilizado, pois os conceitos de perímetro e área podem ser explorados. Nesse momento, a possibilidade de discussões sobre as estratégias utilizadas para se encontrar o resultado final é de valor inestimável para dar segurança e favorecer a autonomia do estudante.

Nessa perspectiva, a Modelagem, como uma metodologia para o ensino de Matemática na Educação Básica, vem ao encontro das expectativas dos estudantes, pois procura favorecer a interação com o seu meio ambiente, uma vez que o ponto de partida é o cotidiano do estudante e, como mostrado nos exemplos, avança-se para o formal a partir do empírico. Quando o educando vê sentido naquilo que estuda, em função da satisfação das suas necessidades e de seus interesses, da realização dos seus objetivos, não haverá desinteresse, pois trabalha com entusiasmo e perseverança. E esse interesse é importante, pois dá início à formação de atitudes positivas em relação à Matemática.

\section{Considerações}

Buscamos, com este trabalho, mostrar uma perspectiva diferenciada para o ensino de Matemática quando mediado pela Modelagem Matemática, vinculada à perspectiva assumida de Educação Matemática. Enfatizamos o interesse e busca de dados, feita pelos estudantes, como princípios para o trabalho com a Modelagem. Procuramos mostrar os desdobramentos 
psicopedagógicos favorecidos nas várias etapas a partir da escolha de um tema. Enfocamos a ruptura com a forma do ensino usual de matemática, proporcionada pela Modelagem Matemática na Educação Matemática. Mostramos ainda, por meio de exemplos, as possibilidades metodológicas oferecidas pela Modelagem, na perspectiva do ensino, da construção dos conceitos e do conhecimento matemático. Trouxemos características diferenciadas, em relação à dinâmica em aula e considerações em relação às ações no encaminhamento das etapas estabelecidas, bem como na abordagem dos conteúdos matemáticos. Ressalte-se a necessidade e a importância de se rever a formação inicial, relativa à Matemática, dos professores que atuam com conteúdos específicos nos anos iniciais. Outros fatores que ensejam mudanças no ensino de Matemática, notadamente nos anos iniciais do ensino fundamental, são a contextualização das situações trabalhadas na Modelagem, as características dos problemas apresentados e as possibilidades pedagógicas e educativas favorecidas por uma metodologia aberta como a que se propõe.

As situações apresentadas no presente trabalho exemplificam uma discussão sobre a construção dos modelos envolvendo duas formas de atuação: 1) junto aos estudantes e professores com a construção de uma representação, também denominada modelo icônico ou reduzido; 2) uma situação que envolveu professores, na qual uma linguagem mais formal na construção do modelo pode ser utilizada e que corresponde a uma formação em serviço do professor que ensina Matemática nos anos iniciais da Educação Básica. A discussão que se faz necessária no ensino de Matemática, principalmente nos anos iniciais, passa, necessariamente, pela utilização de metodologias que favoreçam o pensar e o fazer matemático, desenvolvendo conceitos e construindo o conhecimento mais global, mais total. Dessa forma, surgirá uma nova visão, que envolva o pensamento complexo, proposto por Morin (2006); não o complexo no sentido de difícil, mas aquilo que é tecido junto, multidimensional e que se constitui no conhecimento necessário para formação de nosso estudante presente e que vivencia o século XXI.

\section{Referências}

BASSANEZI, R. C. Ensino-aprendizagem com Modelagem Matemática. São Paulo: Contexto, 2002. BRASIL, Secretaria da Educação Fundamental. Parâmetros Curriculares Nacionais - Matemática. v. 3, 2. ed., Rio de Janeiro: DP\&A, 2000.

BURAK, D. Modelagem matemática: ações e interações no processo de ensino-aprendizagem. Campinas, 1992. Tese (Doutorado em Educação) - Programa de Pós-Graduação em Educação, Universidade Estadual de Campinas - UNICAMP, 1992.

BURAK, D.; ARAGÃO, R. M. R. Modelagem Matemática e relações com a aprendizagem significativa.1.ed., Curitiba: CRV, 2012.

110 DOI: Em andamento. R. Bras. de Ensino de C\&T 
BURAK, D.; KLÜBER, T. E. Educação Matemática: contribuições para a compreensão da sua natureza. Acta Scientiae, v. 10, n. 2, p. 93-106, 2008.

BURAK, D.; KLUBER, T. E. Modelagem Matemática na educação básica, numa perspectiva da educação matemática. In: BURAK D, PACHECO, E. R. (orgs). Educação Matemática: Reflexões e Ações, Curitiba: CRV, p. 147-16, 2010.

DELVIN, K. Os problemas do milênio. Trad. Michelle Dysman. Rio de Janeiro: Record, 2004.

FREIRE, P. Educação como prática da liberdade. 16. ed. Rio de Janeiro: Paz e Terra, 1983.

Pedagogia do oprimido. 17. ed. Rio de Janeiro: Paz e Terra, 1987.

KILPATRICK, J. Fincando estacas: uma tentativa de demarcar a EM como campo Profissional e científico. Zetetiké, v.4, n.5, p. 99-120, 1996.

MORIN, E. Sete saberes necessários à educação do futuro. São Paulo: Cortez, 2006.

NOVAK, D. J. Uma teoria de educação. Trad. Marco Antonio Moreira. São Paulo: Pioneira, 1981.

PANIZZA, M. Ensinar Matemática na Educação Infantil e nas séries iniciais: análise e propostas. Porto Alegre: Artmed, 2006.

RAMOS, C. Excelência na Educação. Rio de Janeiro: Qualitymark, 1994.

RIUS, E. B. Educación Matemática: Reflexión sobre su naturaleza y su metodologia. Educación Matemática, México: Iberoamérica, v.1, n. 2, p. 28-42, 1989a. Educación Matemática: Reflexión sobre su naturaleza y su metodologia. Educación Matemática, México: Iberoamérica, v.1, n. 3, p. 30-36, 1989b.

SANTOS, B. de. S. Um discurso sobre as ciências. 4. ed. São Paulo: Cortez, 2006.

Dionísio Burak - Doutor em Educação pela Universidade Estadual de Campinas, UNICAMP. Docente do Programa de Pós-Graduação em Educação da Universidade Estadual de Ponta-Grossa, UEPG. Docente do Programa de Pós-Graduação em Ensino de Ciências e Matemática da Universidade Estadual do Centro-Oeste, UNICENTRO-PR. E-mail: dioburak@yahoo.com.br.

Márcio André Martins - Doutor em Engenharia Mecânica pela Universidade Federal do Paraná, UFPR. Professor do Departamento de Matemática e do Programa de Pós-Graduação em Ensino de Ciências e Matemática da Universidade Estadual do Centro-Oeste, UNICENTRO-PR. E-mail: mandre@unicentro.br. 